\title{
₹USGS
}

sememensang

Prepared for U.S. Geological Survey and the Advanced National Seismic System National Implementation Committe

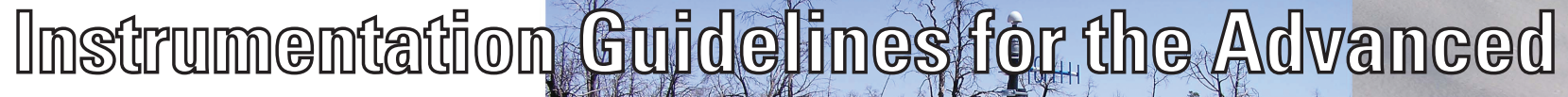

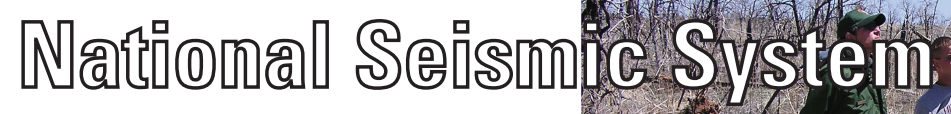
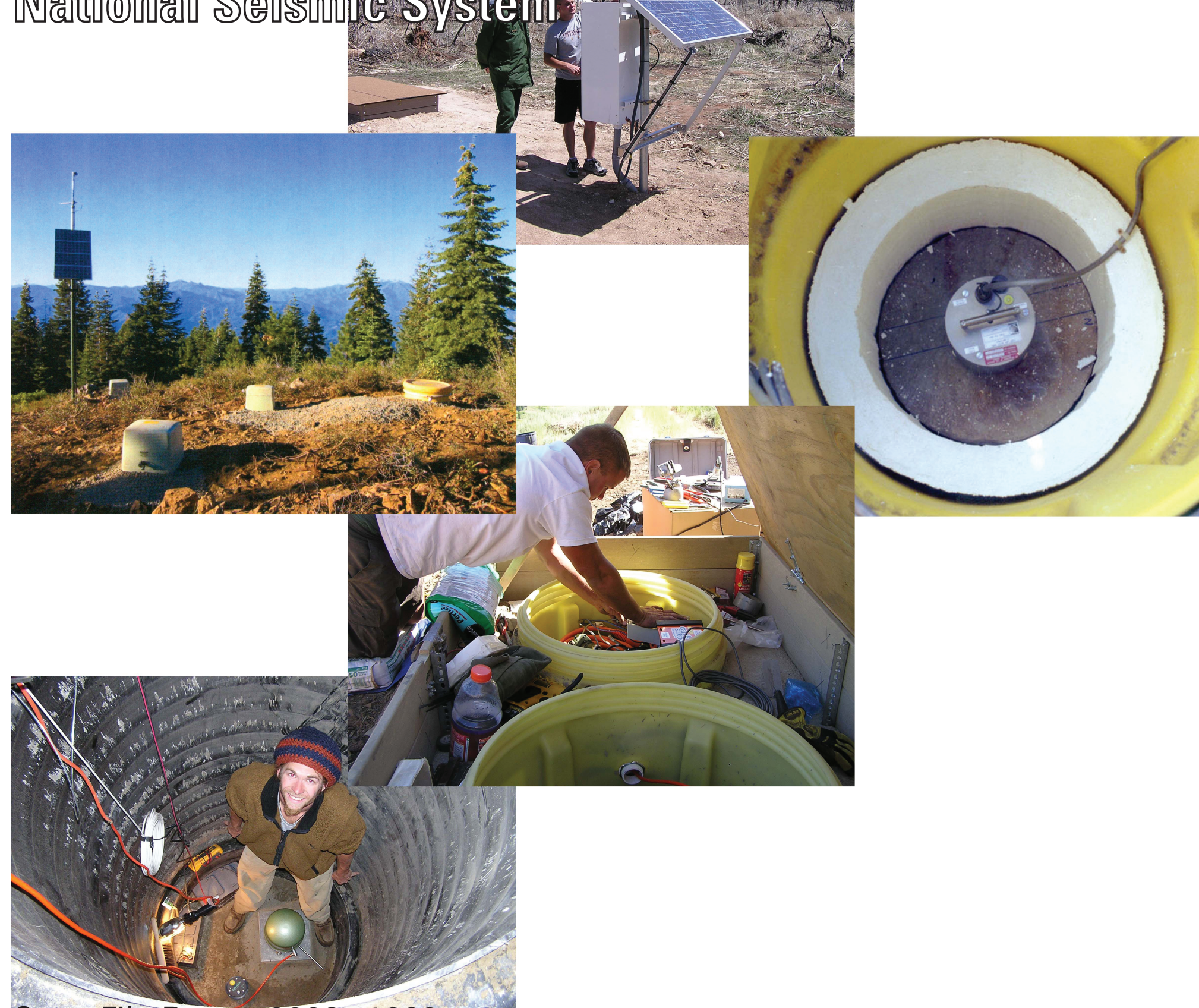

Open-File Report 2008-1262

U.S. Department of the Interior

U.S. Geological Survey 



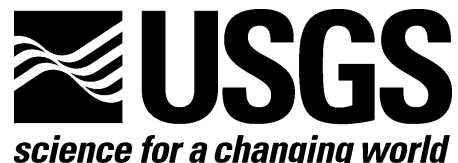

Prepared for U.S. Geological Survey and the Advanced National Seismic System National Implementation Committee

\section{Instrumentation Guidelines for the Advanced National Seismic System}

By the Working Group on Instrumentation, Siting, Installation, and Site Metadata of the Advanced National Seismic System Technical Integration Committee

Open-File Report 2008-1262

U.S. Department of the Interior

U.S. Geological Survey 


\section{U.S. Department of the Interior DIRK KEMPTHORNE, Secretary}

\section{U.S. Geological Survey \\ Mark D. Myers, Director}

U.S. Geological Survey, Reston, Virginia: 2008

For product and ordering information:

World Wide Web: http://www.usgs.gov/pubprod

Telephone: 1-888-ASK-USGS

For more information on the USGS-the Federal source for science about the Earth,

its natural and living resources, natural hazards, and the environment:

World Wide Web: http://www.usgs.gov

Telephone: 1-888-ASK-USGS

Suggested citation:

Working Group on Instrumentation, Siting, Installation, and Site Metadata, 2008, Instrumentation guidelines for the Advanced National Seismic System: U.S. Geological Survey Open-File Report 2008-1262, 41 p.

Available at: http://pubs.usgs.gov/of/2008/1262

Any use of trade, product, or firm names is for descriptive purposes only and does not imply endorsement by the U.S. Government.

Although this report is in the public domain, permission must be secured from the individual copyright owners to reproduce any copyrighted material contained within this report. 


\section{CONTENTS}

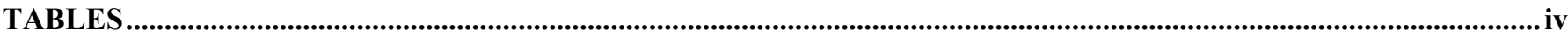

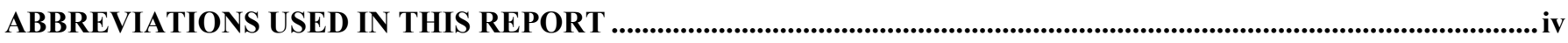

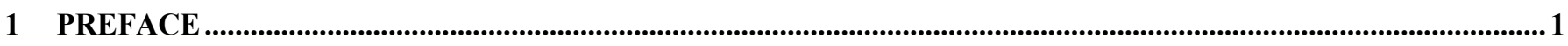

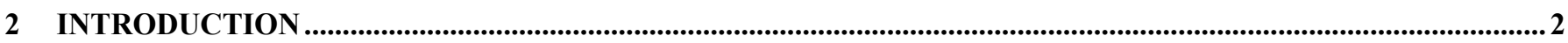

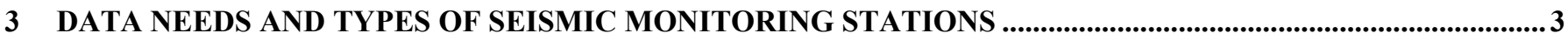

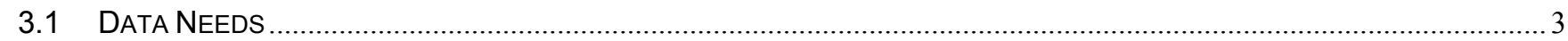

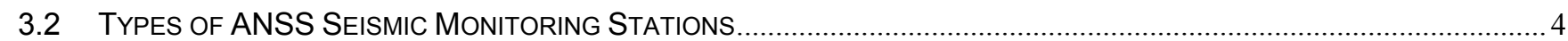

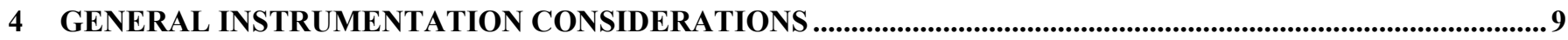

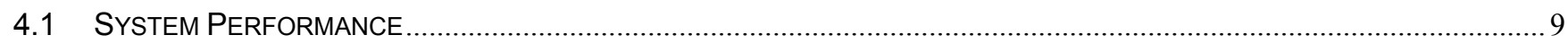

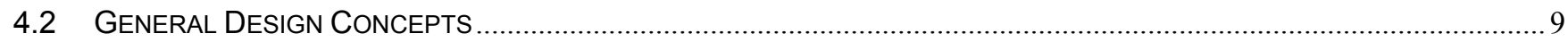

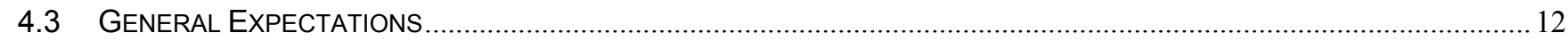

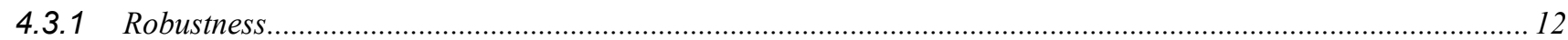

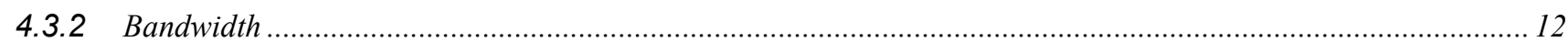

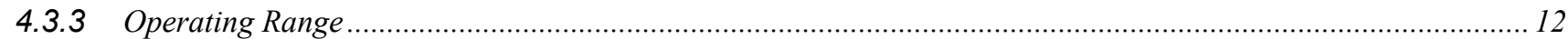

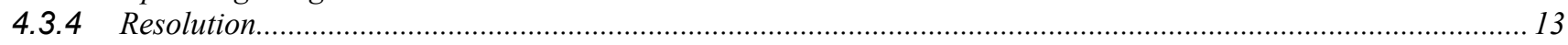

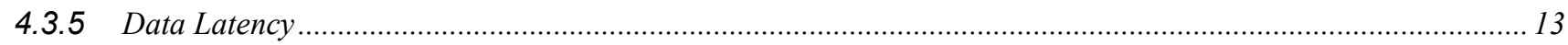

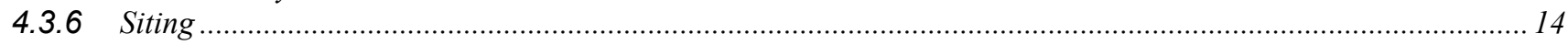

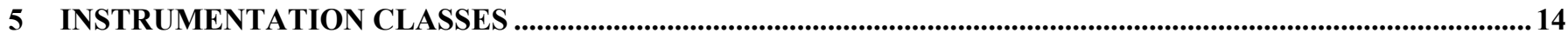

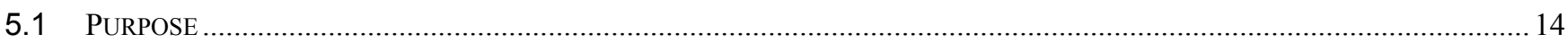

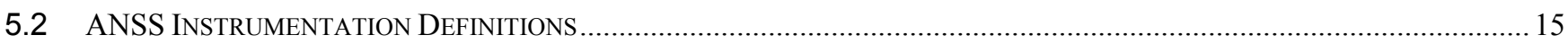

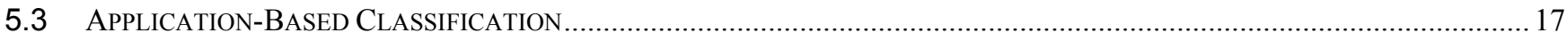

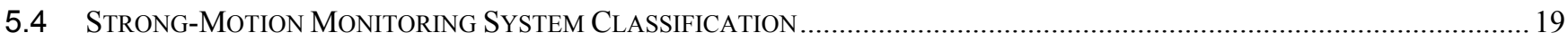

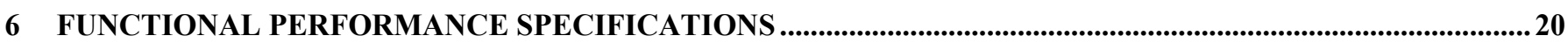

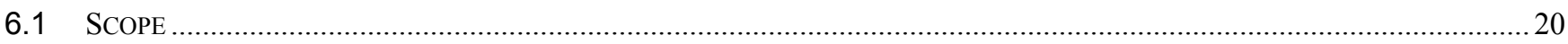

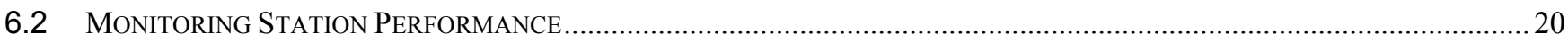

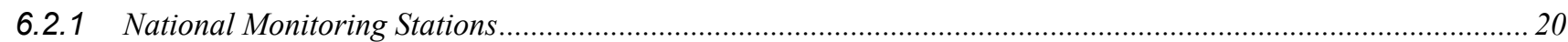

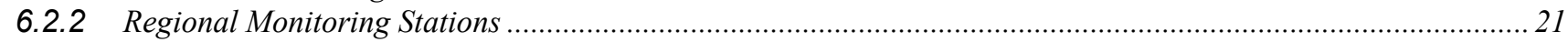

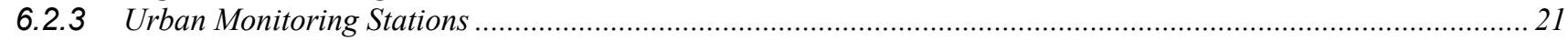

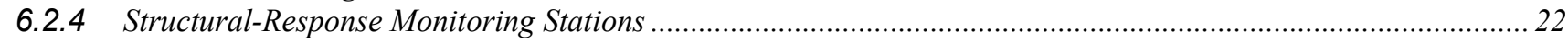

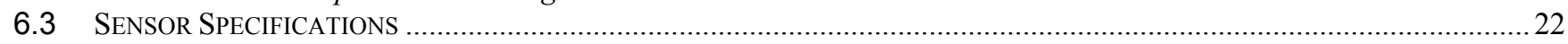

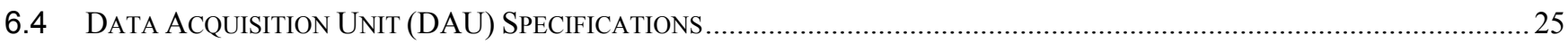

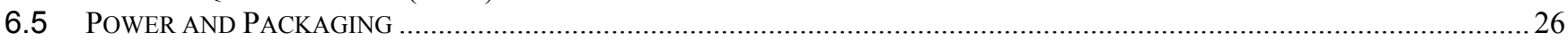

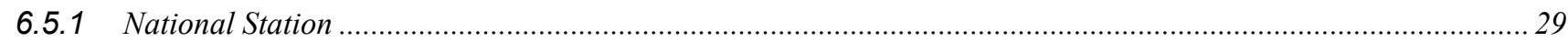

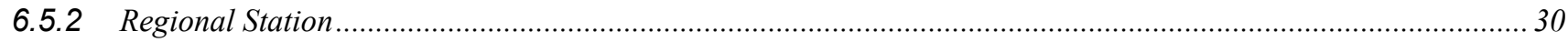

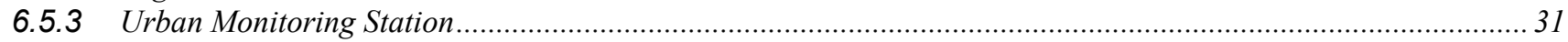

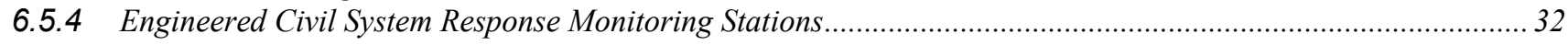

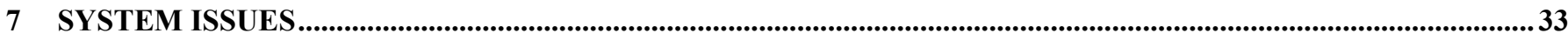

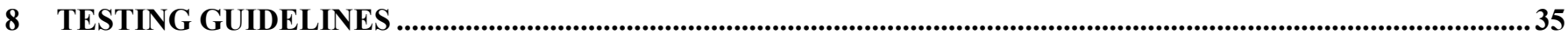

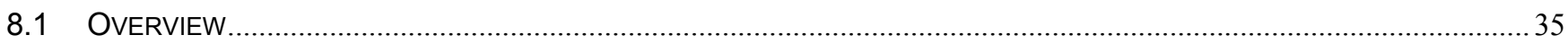

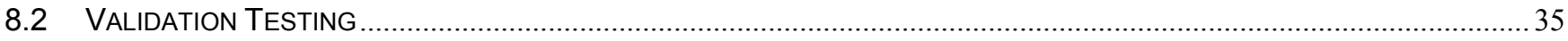

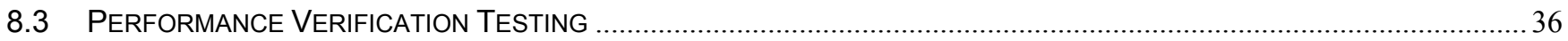

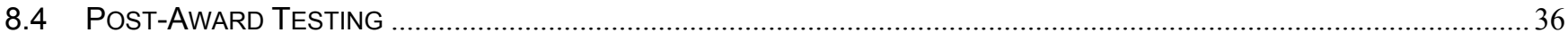

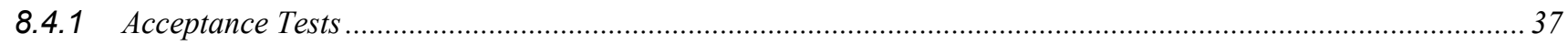

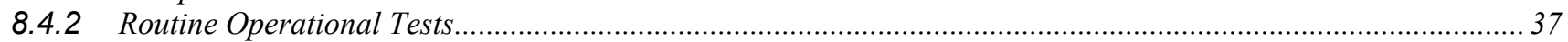

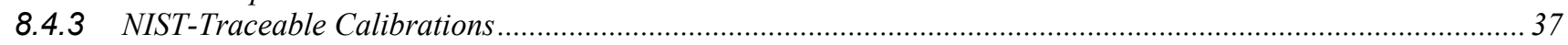

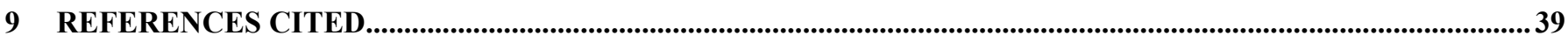

10 APPENDIX: THE WORKING GROUP ON INSTRUMENTATION, SITING, INSTALLATION,

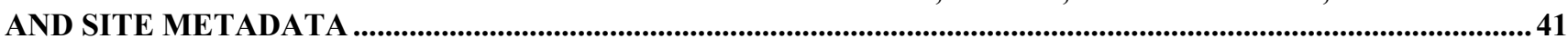




\section{Tables}

1. Selection of instrumentation type and class by ANSS application ..................................... 18

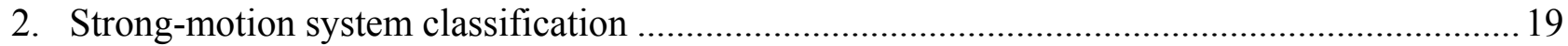

3-5. Performance specifications of:

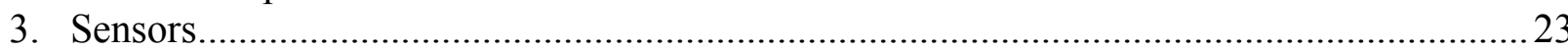

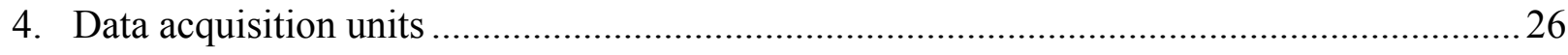

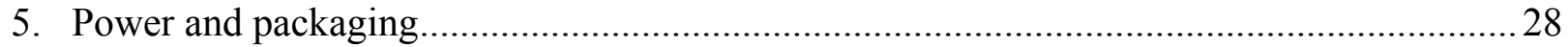

\section{Abbreviations Used in This Report}

$\begin{array}{ll}\mu \mathrm{g} & \begin{array}{l}\text { one millionth of } 1 \mathrm{~g} \text { acceleration } \\ \text { acceleration due to gravity at the Earth's surface } \\ \text { root-mean-square of a given data set } \\ \text { rms } \\ \text { sps }\end{array} \\ \text { ADCles per second } \\ \text { ANSS } & \text { analog to digital converter } \\ \text { DAS } & \text { Advanced National Seismic System } \\ \text { DAU } & \text { data acquisition system } \\ \text { GPS } & \text { global positioning system } \\ \text { IASPEI } & \text { International Association of Seismology and Physics of the Earth's Interior } \\ \text { M } & \text { earthquake magnitude } \\ \text { NIST } & \text { National Institute of Standards and Technology } \\ \text { NTP } & \text { network time protocol } \\ \text { PSD } & \text { power spectral density } \\ \text { SOH } & \text { state of health (message) } \\ \text { U.S. } & \text { United States } \\ \text { VDC } & \text { volts, direct current }\end{array}$

\section{Conversion Factors}

SI to Inch/Pound

\begin{tabular}{cll}
\hline Multiply & \multicolumn{1}{c}{ By } & \multicolumn{1}{c}{ To obtain } \\
\hline kilometer $(\mathrm{km})$ & 0.6214 & mile $(\mathrm{mi})$ \\
meter per second $(\mathrm{m} / \mathrm{s})$ & 3.281 & foot per second $(\mathrm{ft} / \mathrm{s})$ \\
\hline
\end{tabular}




\section{Instrumentation Guidelines for the}

\section{Advanced National Seismic System}

By the Working Group on Instrumentation, Siting, Installation, and Site Metadata of the Advanced National Seismic System Technical Integration Committee

\section{Preface}

This document is a result of the efforts of Working Group D of the Advanced National Seismic System (ANSS) National Technical Implementation Committee to rewrite Chapter 3 of the 2002 ANSS Technical Implementation Guideline document (U.S. Geological Survey, 2002). During 2004 through 2006, Working Group D revised the original Chapter 3 many times and obtained outside review by a broad spectrum of scientists and seismic instrumentation vendors.

We have taken the results of the Chapter 3 revision and created this stand-alone document to address ANSS's need for guidance in its planning for and procurement of new instrumentation.

Members of the Working Group on Instrumentation, Siting, Installation, and Site Metadata are listed in the appendix. A copy of this document and supporting materials, including any subsequent modifications, may be found at http://earthquake.usgs.gov/research/monitoring/anss/documents.php (accessed 15 July 2008). 


\section{Introduction}

This document provides guidelines for the seismic-monitoring instrumentation used by longterm earthquake-monitoring stations that will sense ground motion, digitize and store the resulting signals in a local data acquisition unit, and optionally transmit these digital data. These guidelines are derived from specifications and requirements for data needed to address the nation's emergency response, engineering, and scientific needs as identified in U.S. Geological Survey Circular 1188 (1999). Data needs are discussed in terms of national, regional, and urban scales of monitoring in section 3. Functional performance specifications for instrumentation are introduced in section 4.3 and discussed in detail in section 6 in terms of instrument classes and definitions described in section 5. System aspects and testing recommendations are discussed in sections 7 and 8 , respectively.

Although U.S. Geological Survey Circular 1188 (1999) recommends that the ANSS include portable instrumentation, performance specifications for this element are not specifically addressed in this document. Nevertheless, these guidelines are largely applicable to portable instrumentation. Volcano monitoring instrumentation is also beyond the scope of this document. Guidance for ANSS structural-response monitoring is discussed briefly herein but details are deferred to the ANSS document by the ANSS Structural Response Monitoring Committee (U.S. Geological Survey, 2005). Aspects of station planning, siting, and installation other than instrumentation are beyond the scope of this document. 


\section{Data Needs and Types of Seismic Monitoring Stations}

\subsection{Data Needs}

Guidance for ANSS earthquake monitoring stations includes planning, siting, and installation of suitable instrumentation, all collectively intended to yield the data required to address the goals of the ANSS. Thus the guidance for different types of stations flows directly from ANSS goals and hence from requisite characteristics of data. To meet ANSS performance standards, ANSS data must include measurements that provide the following:

- National monitoring adequate to locate and determine the magnitudes of $\mathrm{M} \geq 3.0$ and larger earthquakes and to quantify salient properties such as focal depth, magnitude, and source characteristics.

- Regional monitoring adequate to provide detailed information about scientifically or societally important earthquake source regions and zones, such as active faults. Events with magnitudes as small as the M2.0-2.5 magnitude completeness level should be observed sufficiently well to determine their location and magnitude. Of particular importance for scientific and engineering purposes is detailed on-scale recording of large earthquakes within $20 \mathrm{~km}$. ShakeMap, earthquake catalogs, and early warning are examples of important ANSS products that depend upon regional monitoring data.

- Ground shaking from felt or damaging earthquakes for scientific and engineering uses, preparation of ShakeMap, rapid response or early warning, public information, and other purposes. The ANSS has prioritized 26 urban areas for ground shaking monitoring.

- Detailed response characteristics of engineered civil systems - buildings, geosystems (such as embankments and earthen dams), and infrastructure (such as bridges and other 
transportation and utility system components) _ for use in improving understanding and predictive modeling of the response of structures and in aiding the response to and recovery from earthquakes.

\subsection{Types of ANSS Seismic Monitoring Stations}

The monitoring systems in the ANSS, as defined in U.S. Geological Survey Circular 1188 (1999), are characterized in terms of the national backbone network, regional networks, and urban monitoring networks. The concept of national-, regional-, and urban-scale monitoring is readily understandable by Federal and State funding agencies and officials and by the general public. However, based on the experience of the initial five years of the ANSS, some refinement within these categories is needed to provide an up-to-date framework for selecting and instrumenting sites as ANSS stations. The traditional distinctions between national, regional, and urban stations, described respectively as having broadband, high-gain short-period, and strongmotion instruments, have blurred. In particular, the various networks have evolved to more effectively monitor and record the continuum of earthquake-caused motions at all frequencies and amplitudes. Another practical consideration relates to budget constraints on full funding; the ANSS now requires an evolutionary approach to achieve its modernization (and other) goals. Thus these revised instrumentation guidelines provide for the inclusion of some legacy seismic instrumentation, consistent with a longer development time and lower rate of capital investment for the ANSS.

In this section, four categories of ANSS seismic-monitoring stations are identified: national, regional, and urban monitoring stations, along with a separate category for specialized instrumentation of structures. The first three categories of station monitor vibratory ground motions; the fourth monitors structural response to these ground motions. As detailed below, 
although these categories do not represent any fundamental change from categories described in U.S. Geological Survey Circular 1188 (1999), their refined description improves the framework that guides the planning and design of ANSS seismic monitoring stations and the performance of their instrumentation.

National monitoring stations are elements of a broad grid or network deployed on a national to global scale (station spacing of hundreds of kilometers) intended to provide uniform seismographic surveillance of the United States and its territories and to support the detection of nuclear tests and tsunamigenic earthquakes outside United States boundaries. Within the ANSS framework, these stations generally are elements of the ANSS-EarthScope national backbone array, the legacy U.S. National Seismic Network, or the Global Seismic Network. Operational responsibilities for these stations currently fall to the U.S. Geological Survey (USGS) in partnership with the National Science Foundation through its Incorporated Research Institutions for Seismology (IRIS)-managed programs. National-scale monitoring emphasizes the recording of longer-period data at very low noise sites with sensitive, low-noise seismographs; accelerometers are included to assure on-scale records of strong shaking, but the placement of the sensors may not meet the requirements of engineering users of strong-motion data.

Regional monitoring stations are elements of regional-to-local-scale grids or networks (station spacing of $\sim 100 \mathrm{~km}$ to $\sim 10 \mathrm{~km}$ ) deployed for the systematic seismic surveillance of all or part of a regional seismic belt, ANSS region, or State jurisdiction, or for high-resolution monitoring of active faults and other seismic source zones within those domains. Within the ANSS framework, such stations generally have been elements of traditional regional seismic networks. Regional monitoring stations require diverse instrumentation and variable station spacing to meet different requirements, such as the assured on-scale recording of moderate to large local earthquakes, high-quality broadband waveforms for moment-tensor inversions, the 
detection and fine spatial resolution of microseismicity associated with active faults, and nearfault recording of strong earthquake ground shaking on both rock and soils needed for earthquake-engineering purposes. These strong-motion records are also an important component of ShakeMap and early warning ANSS products.

Some local-scale monitoring within ANSS regions may be carried out by entities in coordination with the ANSS, such as seismovolcanic monitoring by the USGS volcano observatories, or in some cases independent of the ANSS, such as local monitoring (by public- or private-sector groups) of seismicity associated with impounded reservoirs, geothermal fields, nuclear and other critical facilities, and mining operations. Regional-scale monitoring and localscale monitoring are invariably complementary in space and time, and real-time monitoring and response should be coordinated to the greatest extent possible. In the case of volcano monitoring, regional monitoring stations not only provide information about the surrounding tectonic setting (relevant to the interaction between volcanic and tectonic processes), but they also provide backup on-scale recording in the event of large eruptions that can cause the volcano-monitoring stations to go off scale or even to be destroyed.

Urban monitoring stations are designed for on-scale high-fidelity recording of seismic ground motions in the built environment, especially in areas of moderate to high seismic hazard and high seismic risk. In near real-time (minutes) after an earthquake, Urban monitoring stations provide vital information on the severity and extent of actual ground shaking for impact assessment and emergency response. They also inform earthquake engineers about ground motions that were entered into structural-response monitoring stations, and their data enable predictive modeling of ground shaking in future earthquakes and thus help to improve seismic design and assessment of earthquake damage to structures immediately after an earthquake. In some areas, feasibility studies are underway aimed at using urban monitoring stations (combined 
with regional stations) for early warning of a destructive earthquake that is in progress. Urban monitoring stations will have high clipping levels. Where active faults are close, the instrumentation may provide good on-scale P- and S-wave waveforms for locating microearthquakes (depending on the urban noise levels).

Dense arrays of urban monitoring stations are arrays with small interstation spacing. Currently, urban monitoring stations are typically 3 to $4 \mathrm{~km}$ apart. The variability of ground motions recorded by nearby stations is high and not easily estimated unless the station spacing is reduced to about $1 \mathrm{~km}$ or less (Boore and others, 2003). Such dense arrays of urban monitoring stations are thus needed to confidently interpolate ground motions for use in detailed postearthquake (minutes to months after a damaging earthquake) urban-damage assessments and for other purposes. The dense arrays may be formed as "nested arrays" (Evans and others, 2005), anchored with state-of-the-art class A (see section 5) instrumentation and augmented by class B or other instrumentation. Nested arrays provide high spatial resolution in high priority areas likely to experience moderate to major earthquakes in coming decades and that have one or more of the following characteristics: (1) urban centers with dense populations and dense infrastructure; (2) near-source regions, giving preference to those in and near urban and suburban areas; (3) urban and suburban regions thought likely to suffer from localized effects, such as basin-edge or strong site effects, causing neighborhood-scale "hot spots" of high shaking strength; or (4) National Earthquake Hazard Reduction Program site-class E soils (and the adjacent area) for which few data currently exist but upon which, in some regions, is significant urban and infrastructure development.

Structural-response monitoring stations are arrays of sensors installed in and on structures - buildings, geosystems (geotechnically engineered structures such as landfills and dams), and infrastructure (principally utilities and transportation systems) — to measure the 
earthquake response of such engineered civil systems. Dense geotechnical arrays may augment this class of ANSS stations.

Structure monitoring requires engineering design of the sensor layout and specifications of sensors and data acquisition systems to properly address the application of these data to improving understanding and predictive modeling of engineered civil systems. It is this understanding that leads to advances in seismic design codes and practices and in damage assessment and other immediate post-earthquake activities. Details are beyond the scope of this document but can be found in the ANSS document by the ANSS Structural Response Monitoring Committee (U.S. Geological Survey, 2005). 


\section{General Instrumentation Considerations}

\subsection{System Performance}

The data needs stated in the previous section naturally lead to overall system performance requirements for seismic instrumentation. Generically, the monitoring station instrumentation system (from sensors through data communications) should achieve the following performance:

- Accurate waveforms from first P-wave through surface waves

- On-scale waveforms for all potential earthquakes

- Accurate absolute timing of every sample throughout the record

- Minimum loss of data owing to malfunction of instrumentation or data communication

- Timely transmission of continuous or segmented data for the required analysis applications, including ShakeMap and early warning

- Minimum internal and external contamination by nonseismic noise

- Consistent performance under field conditions.

Detailed specifications for instrumentation performance are provided in section 6 for each of the categories of ANSS monitoring stations. These specifications follow from the system performance goals above.

\subsection{General Design Concepts}

Seismic station and network design are evolving practices, driven by both changing data needs and technological advances. A recent snapshot of the state of practice is found in the International Association of Seismology and Physics of the Earth's Interior (IASPEI) New 
Manual on Seismic Observatory Practice (http://www.iaspei.org, 2002; accessed 15 July 2008).

The design and implementation of ANSS instrumentation is part of this evolution, and this document attempts to provide guidance and organization.

Within this context, many basic decisions about the desired performance of ANSS stations either have been or can be made on the basis of experience, technological trends, and the stated goals of the ANSS. These decisions include the following:

- The need for wide bandwidths and linear high operating range generally dictates feedback sensor designs.

- The need for high resolution dictates onsite digital recording and digital telemetry.

- Seismological research and engineering practice and research require a minimum of three-component linear-motion data. Nevertheless, there is still a useful role in monitoring active faults for single-component, high-gain, short-period sensors in regional or urban monitoring stations that complement three-component translational accelerometers.

- The issue of the three rotational components of motion is a rapidly evolving field of uncertain outcome that may affect the minimum appropriate number of inertial sensors in an ANSS station.

- Technological trends suggest standardizing on Internet protocols (e.g., TCP/IP) for data communication, although use of current and future transmission media options should not be limited.

- Strong-motion data should have continuous access to telemetry whenever possible and practical. However, if cost or technical issues render continuous telemetry impractical, 
dial-up telephone or other intermittent connections are satisfactory if engineered for latency of not more than a few minutes.

- Stations with limited continuous telemetry bandwidth can be accommodated by triggered full-sample-rate event recording, compressing all data, and adopting the highest sample rates consistent with requirements for continuous data transfer.

- The need for complete data implies onsite buffering or backup storage lasting days or longer for all types of stations.

- Reliable communications require error correction and packet retransmission, which implies bidirectional communication. Variable communications latency requires either onsite timing or network-based timing with adequate accuracy.

- Maintenance and reliability concerns similarly imply bidirectional communication and at least daily state-of-health $(\mathrm{SOH})$ messaging from the instrument.

- Small data-delivery latency, an important requirement for early warning, requires short packets and reasonably fast communication speeds with minimal ( $<1$ second transit time) routing or buffering delays.

- Instrumentation systems should be warranted for at least 1 year, and 3 years is desirable; vendors should provide spare parts and service for their systems for at least 10 years after purchase. 


\subsection{General Expectations}

\subsubsection{Robustness}

Data delivery must be reliable and suitable for a variety of communication technologies. Equipment must operate reliably for long periods of time (at least 10 years) in hostile field environments (extreme temperatures, moisture, "dirty" power, other hazards).

\subsubsection{Bandwidth}

The station instrumentation's bandwidth is the range of ground motion frequencies that can be accurately reproduced by the resulting digital data. The overall system bandwidth is a product of the sensor, cabling, and digitizer bandwidths in the field environment of a station. Bandwidth goals for national stations are based on U.S. National Seismic Network functional specifications and are nominally $0.01-50 \mathrm{~Hz}$. The low-frequency specification is based on research needs, whereas the high frequency specification is limited by attenuation at distances comparable with the interstation spacing and by interoperability with regional and urban networks. Bandwidths for regional and urban stations, which are based on experience and identified scientific and engineering needs, are nominally $0.02-50 \mathrm{~Hz}$.

\subsubsection{Operating Range}

The instrumentation system's operating range is the range of amplitudes that can be accurately measured, bounded below by measures of system and site noise or digital resolution and bounded above by the sensor or digitizer clip level. Note that comparing the clipping behavior of transient seismic signals (representable as the rms of a just-clipping sine wave, for example) to an underlying noise level (representable as an rms spectral density, for example) is formally ill posed. Given this fact, the notions of dynamic range and signal-to-noise ratio are undefined. Thus, many investigators have made various arbitrary choices believed to represent 
practical instrument operational conditions. These choices yield results generally called "operating ranges" or "operating-range diagrams" (ORDs). The ANSS formally adopts the detailed methods defined for the Guidelines for Seismometer Testing (GST) as exemplified by J.R. Evans, C.R. Hutt, J.M. Steim, and R.L. Nigbor (written commun., 2008) and recognizes only their "ampORD" and "sdORD", the former definitively and the latter simply as an illustration of likely instrument performance in frequency-domain analyses. In general terms, we define the ampORD range as a ratio of rms values - that of a maximum unclipped sine wave to that of the self-noise floor summed over half octaves. We use time series at particular sampling rates (40 and $200 \mathrm{sps})$ and of particular durations ( $2^{18}$ to $2^{20}$ samples), defined for each instrument type, and take the Walsh-method PSD using defined numbers of 50-percentoverlapping Hann-windowed subsegments. The details of this algorithm are described by those authors and embodied in the MatLab ${ }^{\mathrm{TM}}$ scripts "GST_NoiseAndRangeStandard.m," “GST_NormalizedWelch.m," and related functions, available on-line at http://earthquake.usgs.gov/research/monitoring/anss/documents.php (accessed 15 July 2008).

\subsubsection{Resolution}

The amplitude resolution of a network of instruments is limited by the system noise, bandwidth, self noise and ambient site noise, and the operating range of the instruments. Spatial resolution is limited primarily by the spacing between instruments compared not so much to horizontal wave numbers of the data but to the spatial covariance of observational phenomena.

\subsubsection{Data Latency}

Latencies of only a few seconds for the data at various types of stations are needed to support ShakeMap generation and early warning applications. The combination of onsite storage and short latencies requires that transmission of old data be caught up while current data continue to 
flow uninterrupted. That is, after a communications outage, older data should be transmitted in time-sequential order in parallel with the near real-time data but at a lower priority. This requirement also implies that both vendor-supplied and ANSS-supplied receiving software will tolerate and properly manage and resequence such out-of-sequence catchup data.

\subsubsection{Siting}

Although siting is the province of another portion of ANSS guidance, we note that all sensors — broadband, short period, and acceleration—require some degree of temperature stability to yield useful records; thus, they require thermal insulation. It has not always been the practice to insulate accelerometers and short-period sensors, but we note significant temperature sensitivity in both types of sensor and a particular need for very good baseline stability in acceleration records (which are commonly doubly integrated). Thus, accelerometers and accelerographs require much more thermal insulation than previously applied. Copper-coil geophones should also be insulated at least moderately from diurnal cycling and rapid changes due to local conditions such as sunlight and shadow. Most modern broadband sensors, of course, require heavy thermal insulation.

\section{Instrumentation Classes}

\subsection{Purpose}

This section defines classes of instrumentation based upon data type and quality. These classes, coupled with the types of ANSS monitoring stations defined in section 3.2, provide the framework for organizing performance specifications in section 6 . 


\subsection{ANSS Instrumentation Definitions}

Accelerometer: A sensor that measures acceleration, commonly used as a strong-motion sensor in urban and structural-response networks as well as in national and regional systems to guarantee on-scale recording of moderate and large nearby earthquakes.

BB: Broadband sensor or data acquisition system (DAS); measures seismic motions with wide frequency and amplitude limits generally reaching down to or below site ambient noise. Frequency response includes the long periods/low frequencies needed for global and national seismology purposes.

Class A: Class A instruments (and finer distinctions such as "A-" and "A+") are sensors and data acquisition units at or near the state of the art, currently about 20 to 26 bits resolution in the operating range of the corresponding sensor types.

Class B: Class B instruments (and finer distinctions such as "B-" and "B+") are sensors and data acquisition units that are the next step down in resolution from Class A, currently about 16 to 19 bits resolution in the operating range of the corresponding sensor types.

Class C: Class $\mathrm{C}$ instruments (and finer distinctions " $\mathrm{C}-$ " and " $\mathrm{C}+$ ") are sensors and data acquisition units lower still in resolution, currently about 12 to 15 bits resolution across the operating range of the corresponding sensor types, but which remain superior to the performance of legacy analog film instruments.

Class D: Class D instruments are sensors and data acquisition units with performance comparable to that of legacy analog instruments, about 8 to 11 bits digital resolution or using analog recording. 
DAS: Data acquisition system, a complete seismic monitoring system containing one or more sensors and data acquisition units, and communications hardware. Note that a data acquisition system $=$ a data acquisition unit + sensors.

DAU: Data acquisition unit, a subsystem that acquires, stores, and transmits digital data from one or more sensors. Note that a data acquisition unit $=$ amplifiers $+\mathrm{ADC}+$ storage + telemetry + timing source (global positioning system, NTP, or other).

Sensor: In the ANSS context, a sensor is a device that converts motion to an analog voltage or a digital signal. Ground-motion sensors typically sense translational acceleration or velocity, but they can also sense displacement, strain, force, or rotation.

Seismometer: A sensor that measures velocity or acceleration. In common use, the term indicates a broadband or short-period sensor as distinct from a strong-motion sensor.

ShakeMap: A map (generated by USGS and its partners) of the shaking strength observed or predicted for the region of strong shaking (Wald and others, 1999).

SP: Short-period sensor or data acquisition system that has limited bandwidth at low frequencies (long periods); typically limited to frequencies above $\sim 1 \mathrm{~Hz}$.

SM: Strong-motion sensor or data acquisition system, measures large amplitude motions, to date without the low-amplitude resolution of broadband seismometers.

Strong-motion sensor: A seismometer or accelerometer that measures large-amplitude earthquake motions, up to about $3.5 \mathrm{~g}$ acceleration and $3.5 \mathrm{~m} / \mathrm{s}$ velocity.

Velocimeter: A seismometer or other device sensing ground velocity. 


\subsection{Application-Based Classification}

Several types and classes of instrumentation (including both sensors and DAUs) possess capabilities that span the different ANSS monitoring needs described in section 3 above. Table 1 indicates which instrument type and class are appropriate for each ANSS station type and monitoring application. See the previous section for definitions of the various instrument types and classes.

A table entry of "Primary" indicates that this instrument is the type and class generally recommended for the application. A table entry of "Option" indicates an acceptable instrumentation option or a preferred system in the case of atypical siting conditions or economic and operational limitations.

(Note that "interstation spacing" in table 1 and elsewhere is an approximate average. It is often more realistic to aim for roughly constant interstation spacing but to constrain more closely the equivalent area (in square kilometers) covered be a given station. The conversion, assuming two-dimensional hexagonal symmetry for the array design, is $A=\frac{\sqrt{3}}{4} \xi^{2} \approx 0.433 \xi^{2}$, where $A$ is area per station $\left(\mathrm{km}^{2}\right)$ and $\xi$ is the interstation spacing $(\mathrm{km})$ obtained from table $1 . A$ can be estimated by dividing the total area of the array by the number of stations in the array, with loose margins around the array, by about $\xi / 2$, to compute the area.) 
Table 1: Selection of Instrumentation Type and Class by ANSS Application

\begin{tabular}{|c|c|c|c|c|c|c|c|c|}
\hline \multirow{2}{*}{\multicolumn{2}{|c|}{ ANSS Station Type and Application }} & \multicolumn{7}{|c|}{ Instrument Type/Class } \\
\hline & & $\mathbf{B B} / \mathbf{A}+$ & $\mathbf{B B} / \mathbf{A}$ & BB/A- & SP/A & $\mathbf{S M} / \mathbf{A}$ & $\mathbf{S M} / \mathbf{B}$ & Other \\
\hline \multirow{2}{*}{ } & $\begin{array}{l}\text { Teleseisms and some regional events: } \\
\text { Global (GSN) monitoring }\end{array}$ & Primary & $\begin{array}{l}\text { Option - } \\
\text { Noisy sites }\end{array}$ & & & Primary & & \\
\hline & $\begin{array}{l}\text { Regional events; some teleseisms; some locals: } \\
\text { National monitoring (Interstation Spacing } \\
>70 \mathrm{~km} \text {; ANSS backbone } \sim 300 \mathrm{~km} \text { ) }\end{array}$ & $\begin{array}{l}\text { Option - } \\
\text { quiet sites }\end{array}$ & Primary & $\begin{array}{l}\text { Option - } \\
\text { Noisy sites }\end{array}$ & & Primary & & \\
\hline \multirow{4}{*}{ 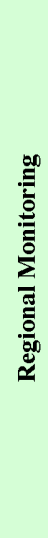 } & $\begin{array}{l}\text { Local and regional events; some } \\
\text { teleseisms: Broadband (Interstation } \\
\text { Spacing } 50-70 \mathrm{~km} \text { ) [Option R.1] }\end{array}$ & & $\begin{array}{l}\text { Option - } \\
\text { quiet sites }\end{array}$ & Primary & & Primary & & \\
\hline & $\begin{array}{l}\begin{array}{c}\text { Primarily local and regional events: } \\
\text { Short period triaxial (Interstation Spacing }\end{array} \\
10-30 \mathrm{~km} \text { ) [Option R.2] }\end{array}$ & & & & Primary & Primary & Option & \\
\hline & $\begin{array}{l}\text { Primarily local and regional events: } \\
\text { Short period vertical (Interstation } \\
\text { Spacing } 10-30 \mathrm{~km} \text { ) [Option R.3] }\end{array}$ & & & & Option & Primary & Option & $\begin{array}{l}\text { Class C or D } \\
\text { Option }\end{array}$ \\
\hline & $\begin{array}{l}\text { Strong-Motion Regional Coverage: } \\
\text { Strong-motion sensor only (Interstation } \\
\text { Spacing } 3-30 \mathrm{~km} \text { ) [Option R.4] }\end{array}$ & & & & & Primary & Option & $\begin{array}{c}\text { Class C or D } \\
\text { Option }\end{array}$ \\
\hline \multirow{5}{*}{ 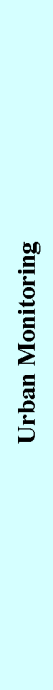 } & $\begin{array}{l}\text { Strong-motion and Regional: } \\
\text { Inclusive of broadband (Interstation } \\
\text { Spacing } 50-70 \mathrm{~km} \text { ) [Option U.1] }\end{array}$ & & $\begin{array}{l}\text { Option - } \\
\text { quiet sites }\end{array}$ & Primary & & Primary & & \\
\hline & $\begin{array}{l}\text { Strong-motion and Active-Fault: } \\
\text { Includes short period triaxial (Interstation } \\
\text { Spacing } \leq 4 \mathrm{~km} \text { ) [Option U.2] }\end{array}$ & & & & Primary & Primary & & \\
\hline & $\begin{array}{l}\text { Strong-motion and Active-Fault: } \\
\text { Includes short period vertical (Interstation } \\
\text { Spacing } \leq \mathbf{k m} \text { ) [Option U.3] }\end{array}$ & & & & Option & Primary & Option & \\
\hline & $\begin{array}{c}\text { Strong-motion only: } \\
\text { Strong-motion sensor only (Interstation } \\
\text { Spacing } \leq 4 \mathrm{~km} \text { ) [Option U.4] }\end{array}$ & & & & & Primary & $\begin{array}{l}\text { Option - } \\
\text { Noisy sites }\end{array}$ & Class C Option \\
\hline & $\begin{array}{c}\text { Strong-motion only: Infill for } \\
\text { Dense strong-motion array (Interstation } \\
\text { Spacing } \leq 2 \mathrm{~km} \text { ) [Option U.5] }\end{array}$ & & & & & & Primary & $\begin{array}{l}\text { Class C or D } \\
\text { Option }\end{array}$ \\
\hline \multirow{2}{*}{ } & $\begin{array}{c}\text { Reference station(s) (configuration } \\
\text { designed for each structure and } \\
\text { corresponding, specified data requirements) }\end{array}$ & & & & & Primary & Option & GPS Sensors \\
\hline & $\begin{array}{l}\text { Structural array (instrumentation and } \\
\text { configuration designed for each structure and } \\
\text { corresponding, specified data requirements) }\end{array}$ & & & & & Option & Primary & $\begin{array}{l}\text { Displacement, } \\
\text { Strain, and GPS } \\
\text { Sensors }\end{array}$ \\
\hline
\end{tabular}




\subsection{Strong-Motion Monitoring System Classification}

Although strong-motion monitoring is included in the scope of the application-based classification in the previous section, it is distinct enough to warrant additional discussion.

In addition to the current and planned ANSS urban monitoring stations, there are plans for development of a higher density of stations in some urban areas by using lower-cost and lowerresolution instruments. "Urban dense" stations may be operated by private industry, amateurs, schools, and sometimes by the ANSS. Although of lower amplitude resolution than the primary ANSS urban instruments, these stations will yield valuable results for ANSS engineering and research. They will add spatial resolution to ANSS networks and are useful also in situations where budgets are limited or sites are noisy.

Table 2 defines classes A-D of strong-motion systems in terms of resolution and estimated cost.

Resolution in table 2 is defined by the ampORD analysis of J.R. Evans, C.R. Hutt, J.M. Steim, and R.L. Nigbor (written commun., 2008).

Cost is an estimate of the current retail cost (quantity 1) for a complete strong-motion DAS from sensors through DAU through communications hardware.

\section{Table 2. Strong-motion system classification.}

[DAS, data acquisition center; $\mathrm{dB}$, decibels; $\mu \mathrm{g}$, micrograms]

\begin{tabular}{ccccc}
\hline $\begin{array}{c}\text { Strong-motion } \\
\text { DAS class }\end{array}$ & $\begin{array}{c}\text { DAS resolution } \\
(\boldsymbol{\mu g})\end{array}$ & \multicolumn{2}{c}{ DAS dynamic range (broadband) } & $\begin{array}{c}\text { Approximate 2007 cost } \\
\text { of one DAS } \\
\text { (US \$) }\end{array}$ \\
\cline { 3 - 4 } & $<7$ & $\mathrm{~dB}$ & Bits & 10,000 \\
$\mathrm{~A}$ & $7-107$ & $87-111$ & $\geq 20$ & 5,000 \\
$\mathrm{~B}$ & $107-1709$ & $63-87$ & $\geq 16$ to 20 & 3,000 \\
$\mathrm{C}$ & $\geq 1709$ & $<63$ & $<12$ & 1,000 \\
$\mathrm{D}$ & & & & \\
\hline
\end{tabular}




\section{Functional Performance Specifications}

\subsection{Scope}

"Functional performance specifications" are defined herein as detailed criteria or metrics for the desired levels of performance from numerous elements of ANSS instrumentation. These specifications were developed from the ANSS data needs summarized in section 3.1.

The specifications in this section are not intended to be directly used as procurement specifications but are a resource for procurement of ANSS and ANSS-compatible seismic instrumentation. Vendors should adhere to procurement requirements.

The following sections present station performance goals, specifications for sensors, specifications for DAUs, and commentary for each ANSS monitoring-station type.

\subsection{Monitoring Station Performance}

Overall functional performance goals for each type of ANSS monitoring station are provided below.

\subsubsection{National Monitoring Stations}

National stations must meet the diverse needs of national and global source monitoring and the needs of national and global earthquake research, and they must capture strong ground motion for nearby events. They should also be interoperable with regional stations, at least matching their performance. Specific performance requirements are as follows:

- High resolution in the band $0.01-15 \mathrm{~Hz}(0.00278-15 \mathrm{~Hz}$ for global stations), on-scale recording, and latencies less than about $30 \mathrm{~s}$. 
- Resolution below ambient noise in the band $0.04-10 \mathrm{~Hz}(0.00278-10 \mathrm{~Hz}$ for global stations), on-scale recording, high fidelity, and complete continuous data.

- Upper band limit of $50 \mathrm{~Hz}$, thus 100-200 sps, where interoperable with and supporting regional stations sampling at those rates.

- For the strong ground motion component, sensitivity in the band $0.02-50 \mathrm{~Hz}$, a clip level of $3.5 \mathrm{~g}$, constant absolute sensitivity, low hysteresis, and $\geq 200$ sample-per-second recording.

\subsubsection{Regional Monitoring Stations}

Regional stations must monitor both small and infrequent events, meet the needs of national and regional seismological research, and capture strong ground motions. Specific performance requirements are as follows:

- High resolution in the band 0.02 to $35 \mathrm{~Hz}$, on-scale recording, sampling at least at 100 sps and preferably 200 sps (to oversample for better time resolution or to allow for the transition band of analog anti-alias filters), and latencies less than about $10 \mathrm{~s}$.

- Resolutions below ambient noise in the band $0.04-10 \mathrm{~Hz}$, on-scale recording, high fidelity, and complete, continuous data.

- For the strong ground motion component, sensitivity in the band $0.02-50 \mathrm{~Hz}$, a minimum clip level of 3.5 g peak, constant absolute sensitivity, low hysteresis, and at least 200 sps recording.

\subsubsection{Urban Monitoring Stations}

Urban monitoring stations must provide the following: (1) information about the strongmotion wave field and local site effects with little ("reference") or no ("free field") contamination 
from manmade structures; (2) data quickly enough to produce ShakeMaps and other information products within $5 \mathrm{~min}$. for emergency response, public media, and rapid recovery purposes; and (3) broadband or short-period sensors at sites where active faults or regional planning considerations indicate the need. Specific performance requirements are as follows:

- Resolutions below $100 \mu \mathrm{g}$ over the band $0.02-50 \mathrm{~Hz}$

- On-scale recording to a minimum clip level of $3.5 \mathrm{~g}$ peak

- Locally triggered data storage with optional continuous data streaming

- Latency of a few minutes after detrigger

- Sensitivity in the band $0.02-50 \mathrm{~Hz}$, constant absolute sensitivity, low hysteresis, and recording to at least 200 sps.

\subsubsection{Structural-Response Monitoring Stations}

Specifications for the structural-response class of ANSS station are largely the same as those for urban monitoring stations. There can be unique sensors or subsystems for structural monitoring, such as strain, displacement, shock, or load sensors, that are not used elsewhere within the ANSS. Further performance requirements are found in the guidance document by the ANSS Structural Response Monitoring Committee (U.S. Geological Survey, 2005).

\subsection{Sensor Specifications}

Table 3 contains specifications for various performance metrics relating to sensors, including broadband, short-period, and strong-motion sensors. 
Table 2: Sensor performance specifications (in two panels)

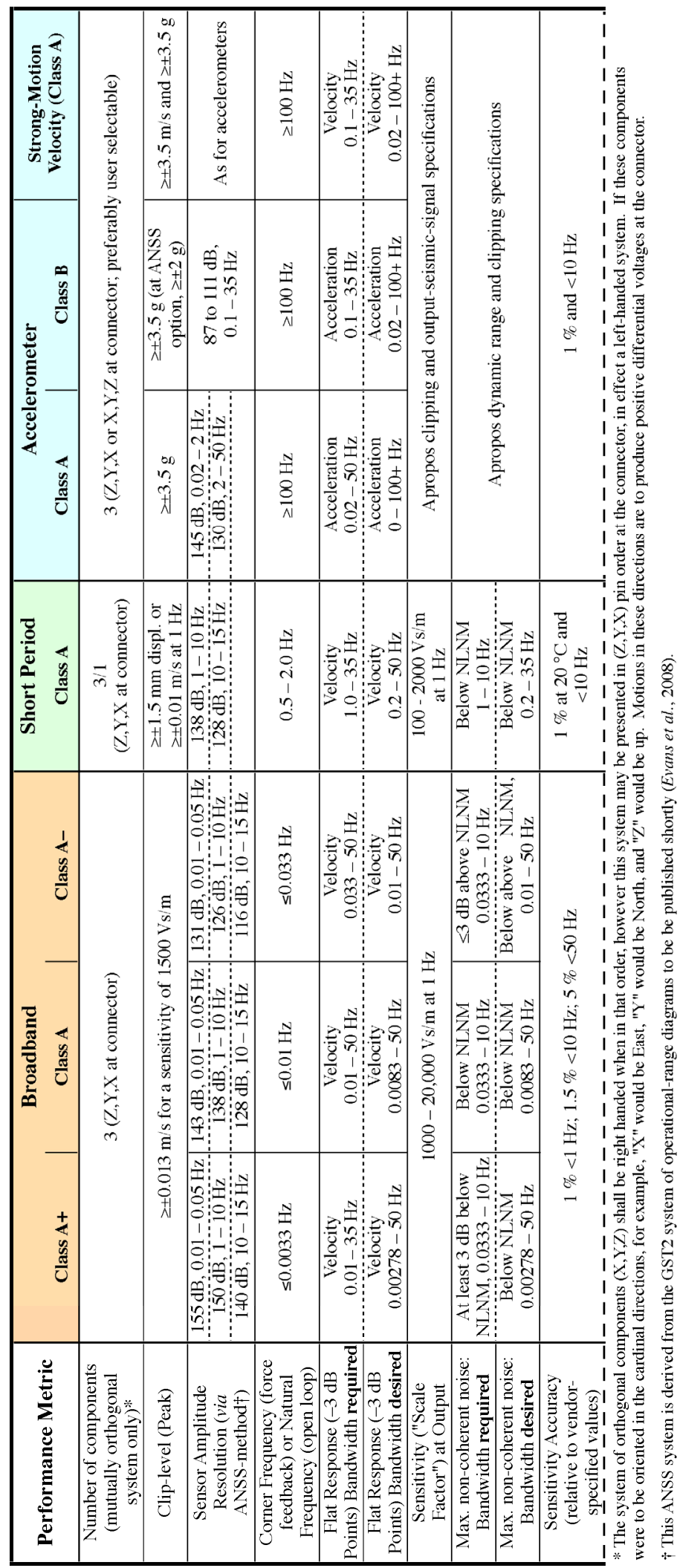




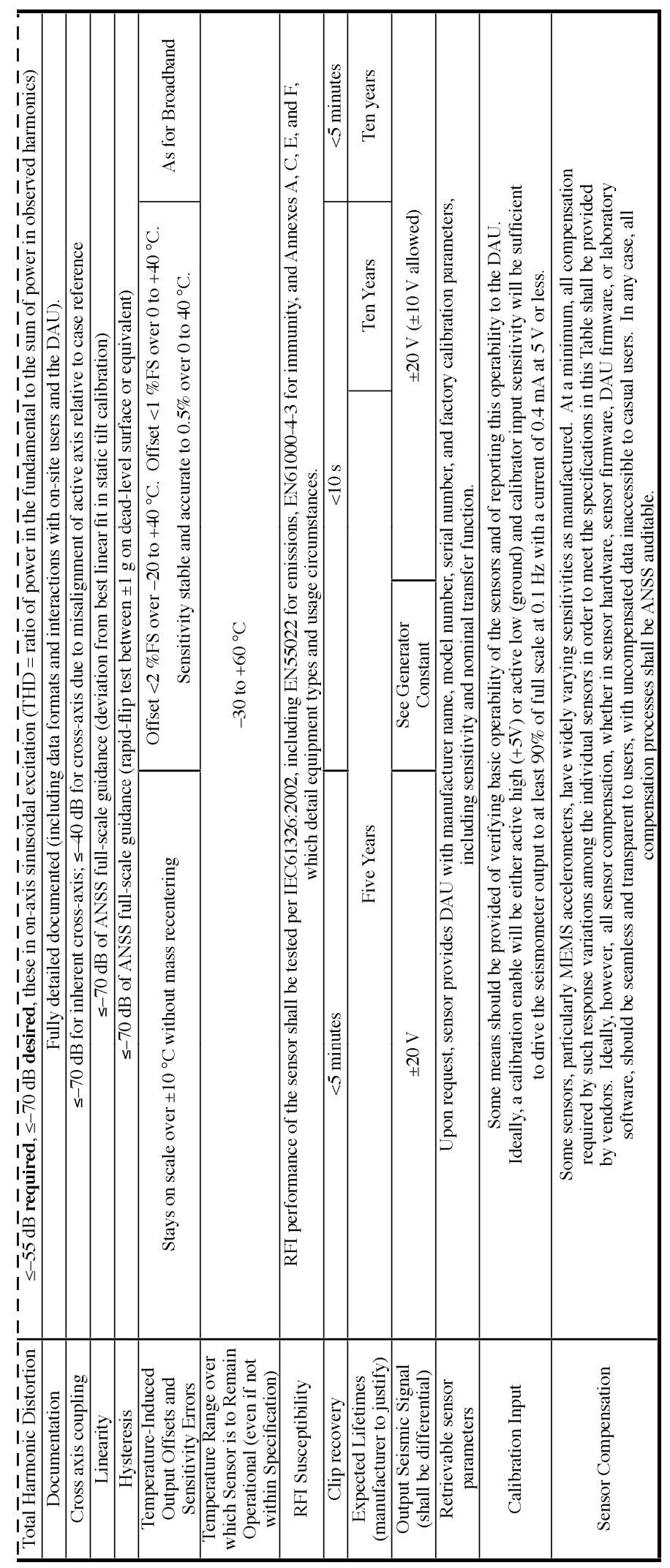




\subsection{Data Acquisition Unit (DAU) Specifications}

Table 4 contains specifications for performance metrics related to data acquisition units for all station types.

\subsection{Power and Packaging}

Power requirements are a critical parameter for seismic station design, and packaging of the system components is important for long-term reliability. Performance specifications for power and for several quantifiable aspects of packaging are provided in table 5. 
Table 3: DAU performance specifications (in two panels)

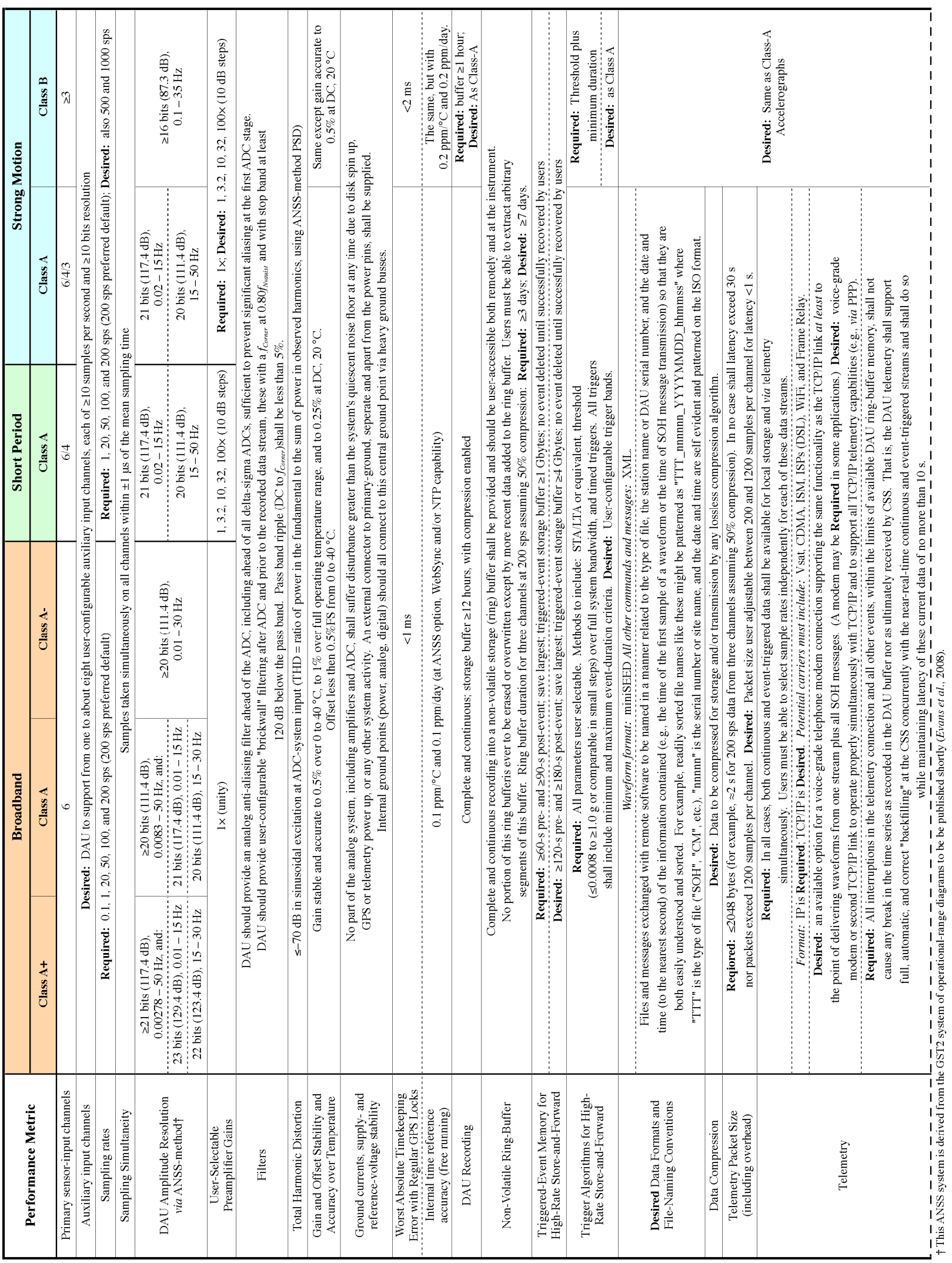




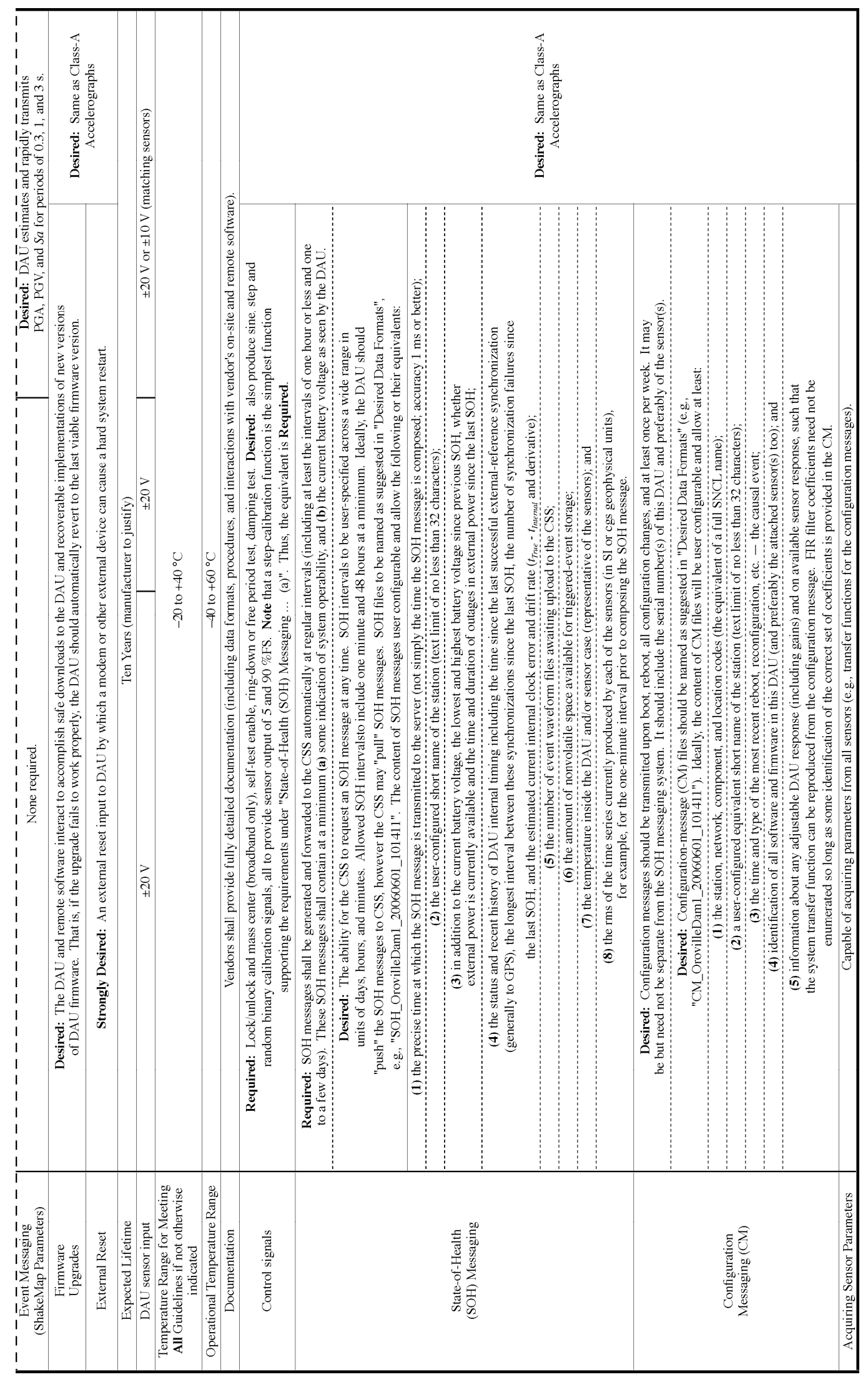




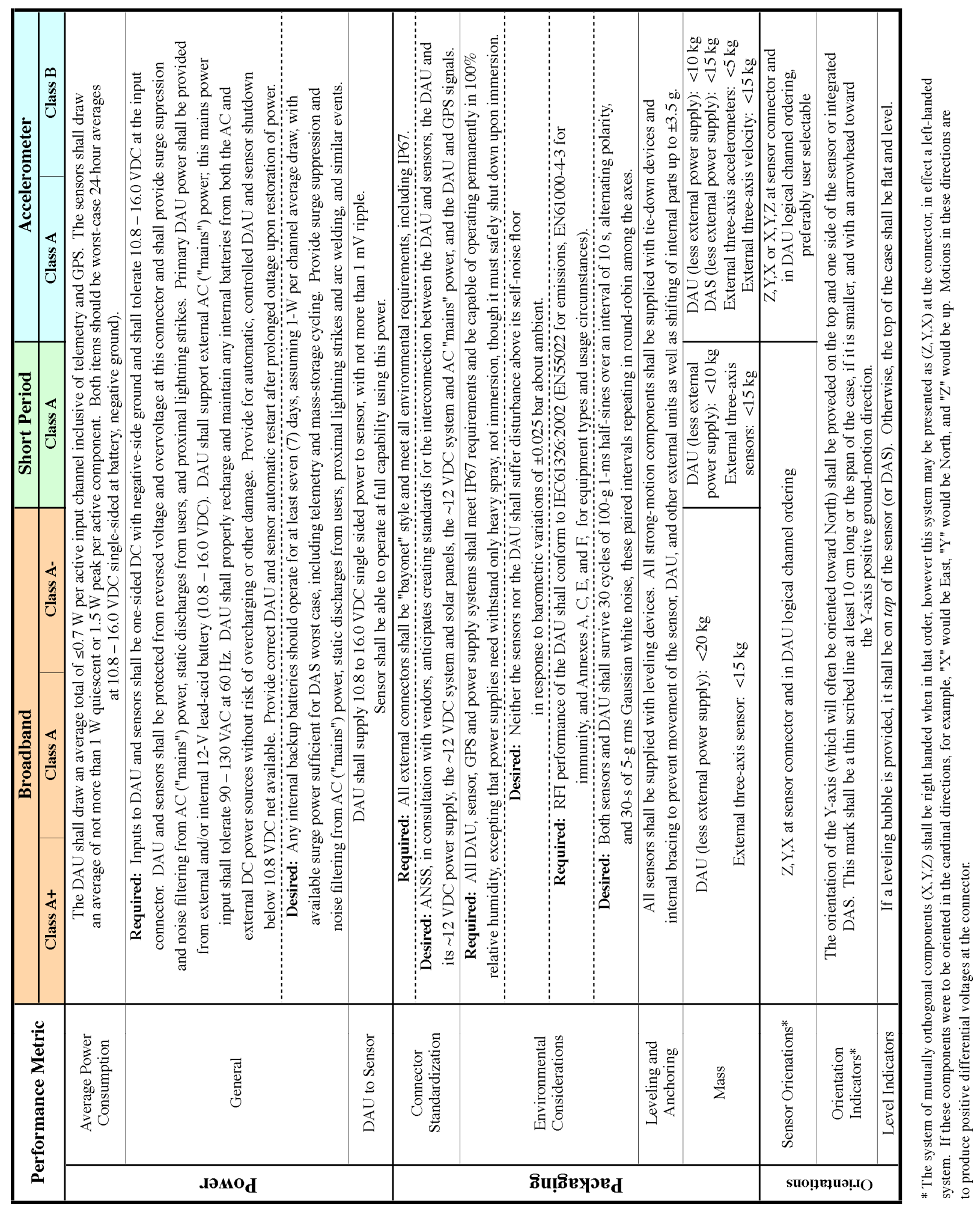




\subsubsection{National Station}

Broadband weak-motion seismometers are suitable for national stations, supplemented by strong-motion sensors and a 200 sps data stream (table 1). Stations meeting the specifications of the Global Seismographic Network (GSN) would require Class BB/A+ instrumentation, with emphasis on low noise at long periods. National monitoring stations (interstation spacing about 70-280 km) need to resolve higher-frequency bands, with less emphasis on the long-period band. The best of these stations (at low noise sites) would require Class BB/A instrumentation, whereas the noisiest of these stations would use Class BB/A- instrumentation. The bandwidth and operating range specifications listed in table 1 reflect these differing requirements. The maximum noncoherent sensor noise specifications were derived from contour plots across the United States of seismic noise in various bands, as observed by the U.S. National Seismic Network.

The DAU digitizer resolution requirements are matched to the operating range of the seismometers. Note that all DAUs should be capable of sampling at a rate of at least $200 \mathrm{sps}$, which is also the preferred sample rate where practical. Less resolution is needed to resolve signals at higher frequencies (for instance, up to $15 \mathrm{~Hz}$ versus $15-30 \mathrm{~Hz}$ ) because of typically higher noise levels in these bands. Also, it is well known that digitizers running at higher sampling rates are not capable of the high resolutions possible at lower sample rates, although that advantage can be recovered by properly downsampling a higher-rate data stream.

The power system should meet the specifications listed in table 5. State-of-health (SOH) monitoring functions for the power system should reside entirely within the DAU and should be composed of the following: 
- The DAU should sample at least once per second (and at least five times faster than the interval at which the state-of-health message is transmitted, whichever is faster) the $\sim 10.8$ to $16 \mathrm{VDC}$ voltage input to the DAU by the power system, as referenced to the master ground. This sampling should be at a resolution of 0.01 VDC or finer.

- For the interval between state-of-health messages, the DAU should calculate the mean, minimum, maximum, and rms of this power voltage to a precision of $0.01 \mathrm{VDC}$ or finer.

- The DAU should report these four values in each of its state-of-health messages to an accuracy of $0.01 \mathrm{VDC}$ or finer.

- To facilitate diagnosis of line-power failures and other disruptions to power systems, DAU state-of-health messages should be reported at least four times per day and preferably 12 or more times per day. The DAU should, if feasible, also send an emergency state-of-health message containing the same information just prior to when the DAU shuts down for loss of power or other fault condition.

\subsubsection{Regional Station}

The seismometer may be the same as for a national station. However, the noise requirements are less stringent and there is a need for response to higher frequencies owing to the interstation spacing of about 50-70 km, implying the possible use of a different seismometer that meets these specific requirements.

A single vertical or three components of short-period seismometer may be appropriate for some active-fault monitoring applications. These short-period components should be in addition to three-component strong-motion sensors.

The DAU for a regional station needs somewhat less resolution than a DAU for a national station. Note that zero-phase fine-impulse-response (FIR) filters used in modern digitizers are 
known to create acausal artifacts that can cause problems for automatic phase-arrival time picks from stations near an event. Despite this drawback, it is recommended that zero-phase filters should be used for regional stations because of the enhanced value for later research. It is suggested that acausal artifacts can be reduced to acceptable levels for near-real-time processing by attenuating high frequency energy by use of minimum-phase filters. Alternatively and preferably, it is possible to correct for the effects of minimum-phase filters through the use of a filter designed specifically for the purpose.

\subsubsection{Urban Monitoring Station}

As indicated by tables 3 and 4, the ANSS is interested in 3-, 4-, and 6-channel systems. Further, the sensors, the DAU, and the power system may be delivered as an integrated system or as physically separate modular units connected with cables.

In the latter case, the ANSS may collaborate with manufacturers to standardize connectors and modularization schemes. Tentatively, the sensor cable should be included with the sensor, the global positioning system (GPS) cables with the GPS receiver, the power cables with the DAU, external data-storage unit cables with that unit, and any telemetry cables with the telemetry transmitter.

With 21 bits of resolution and a Class A strong-motion sensor, a magnitude 2.5 event at 10 $\mathrm{km}$ epicentral distance should be well recorded for use of the entire waveform, whereas a magnitude 1.8 event at more than $35 \mathrm{~km}$ can be recorded well enough to determine the peak accelerations. Ambient seismic noise is likely to be the limiting factor in station performance, not resolution.

For Class B strong-motion systems, the expectation is that events of primary engineering and emergency response interest will be well recorded, including those that are likely to exhibit 
nonlinear soil response. Additionally, studies of the causes of spatial variation in strong ground motions are a critical target, beginning with nearby events of $\mathrm{M}>3$, which should be well recorded. Life-cycle cost is a critical issue for Class B systems. It includes purchase, installation, and maintenance costs and may imply the ability to download system software upgrades from a remote server and reboot, with crash recovery.

While most ANSS data recording uses (and in the future will to an even greater extent use) continuous recording, local buffering, and telemetry, there remains a need to use at least basic triggering to (1) assure backup recording of the critically needed rare near-fault, National Earthquake Hazard Reduction Program (NEHRP) site-class E, and strong urban recordings; (2) temporarily boost sample rates during large events, particularly at regional and national stations; (3) maintain the option of reducing telemetry costs by operating selected systems only in triggered mode; and (4) operate Class B monitoring systems principally or only in triggered mode to lower their life-cycle costs.

Table 4 specifies a minimum complement of trigger algorithms and specifics but leaves open the field of triggering to include the range of more sophisticated triggers implemented in many current instrumentation DAUs. It is also desirable for users to be able to supply their own trigger algorithms to DAUs with a minimum of (ideally, no) manufacturer intervention and in a highlevel language such as $\mathrm{C}$.

\subsubsection{Engineered Civil System Response Monitoring Stations}

Specifications for this class of ANSS station are largely the same as those for urban monitoring stations. There can be unique sensors or subsystems for structural monitoring, such as strain, displacement, or load sensors, that are not generally used elsewhere within the ANSS. 
Further commentary on this type of ANSS station is found in the guidance document by the ANSS Structural Response Monitoring Committee (U.S. Geological Survey, 2005).

\section{System Issues}

In addition to the element-level functional performance specifications described in the previous section, the design, specification, and installation of seismic systems must consider external environmental effects including the following:

- Moisture: humidity, rain, snow, temporary submersion due to flooding, and salt drift near coastlines

- Temperature, both high and low

- Wind, as it may affect physical integrity of the system components as well as seismic noise

- Sun, as it affects short-term thermal changes and long-term material degradation

- Pressure, as it affects sensor noise

- Radio frequency interference, both from external and internal sources

- Magnetic interference from external sources

- Rigorous anchoring of strong-motion sensors and other components at such sites to prevent resonance, banging, and other internal noise as well as intra-event shifting at \pm 3.5 g peak.

Some of the specifications in the previous section cover these environmental effects for components, but not necessarily for the overall installed systems. In addition to environmental 
effects, the design, specification, and installation of DASs for ANSS applications should address the following general system issues:

- Need for standardization among vendors of external connectors for power, sensors, communications, and timing

- Provisions for field leveling of sensors (such as leveling legs) as well as periodic automatic leveling, principally for broadband sensors

- Robust anchoring of strong-motion systems and all other components at sites with strongmotion sensors

- System and component weight (including power systems) where important, such as in remote field installations

- Need for standardized control and data communications interfaces, including at least the ability to use a wide range of hardware and software computer platforms

- Need for thorough documentation of components and as-installed systems to enable operation, maintenance, and confident use of the data

- Maximization of remote operation and maintenance functions (for example, state-ofhealth messaging and remote adjustment of operating parameters, including at least gains, filter settings, sampling rates, and trigger settings).

System issues may be network dependent and site dependent; a thorough description is beyond the scope of this document. 


\section{Testing Guidelines}

\subsection{Overview}

In addition to manufacturers' validation testing for their own purposes, performance may be verified by testing as part of the procurement process. The ANSS may test samples of all items in the specifications sections above that are applicable to that particular sensor, DAU, or DAS. Random and targeted acceptance tests of instruments (the deliverables) may be performed by the ANSS to verify ongoing compliance with specifications; all or portions of applicable specifications may be tested as deemed appropriate by the ANSS. Routine operational tests may be performed by the ANSS to maintain data quality and monitor ongoing performance of instruments, testing all or portions of applicable specifications as deemed appropriate by the ANSS. From time to time, the ANSS may perform or contract out National Institute of Standards and Technology (NIST)-traceable calibrations of various instruments to test performance of its networks or the compliance of deliverables to contract requirements. ANSS may during such calibrations test all or portions of applicable specifications, as it deems appropriate.

The intention of vendor and ANSS testing described here is to reduce the lifecycle cost of these instruments and to verify their performance. Therefore, larger initial expense is tolerated where it is likely to reduce long-term expense, instrument failure, and uncertainty in performance, reliability, or the validity of the data for their intended uses.

\subsection{Validation Testing}

Validation testing by the manufacturer demonstrates that the product design satisfies its intended usage. Such high-level testing is generally part of the design process and as such may be used by vendors to prepare for performance verification tests described in section 8.3 . 
Validation testing may be part of the vendors' research and development, prequalification, and manufacturing-development processes leading to their confidence in their product.

\subsection{Performance Verification Testing}

Performance verification testing confirms that products meet specified performance requirements. In the ANSS context, this testing should be a formal step in which vendors complete formal performance verification testing (often under close ANSS observation) of final versions of two randomly selected sensors, two randomly selected DAUs, or two randomly selected DASs (depending on the item bid). These tests should meet a high level of quality assurance, with NIST-traceable measurement of performance metrics and within some kind of quality assurance environment such as International Organization for Standardization (ISO) 9000. Test specifications should be prepared in advance of any procurement. All resulting data and analyses should be provided to the ANSS in sufficiently complete form that the ANSS can analyze the test data and confirm test results.

It is recommended that two or more test specimens be selected at random from a batch of eight or more final manufactured copies of final versions of the proposed sensor, DAU, or DAS. The ANSS may require that tests be witnessed in person by ANSS staff or their representatives and possibly recorded in video and sound (by the ANSS) for documentation and external review. The ANSS may require that original test data be supplied to the witness for direct transfer to the ANSS at the time of the testing.

\subsection{Post-Award Testing}

The ANSS may perform three additional types of tests on instrumentation during procurement or operation, as follows: 


\subsubsection{Acceptance Tests}

Acceptance tests of randomly selected or suspect units may be performed upon delivery or shortly afterward to verify whether the components and systems meet ANSS contract specifications. If they do not, three alternatives exist: the components or systems should be returned to the vendor for repair; additional units of similar manufacturing lots or serial numbers should be tested by the ANSS; and if a pattern of vendor noncompliance emerges, the vendor's history may be considered substantially unresponsive in subsequent requisitions.

\subsubsection{Routine Operational Tests}

The ANSS will perform various routine on site and laboratory operational tests to verify the continuing performance of the DASs and supporting systems it operates. These routine operational tests may include automatic self-testing by the DAS, manual or automated sensor tests, manual or automatic voltage checks, and other field tests by maintenance personnel. These tests may be similar to Acceptance or to Performance Verification testing but will generally be less extensive.

\subsubsection{NIST-Traceable Calibrations}

From time to time, the ANSS may deem it appropriate to perform or to contract out NISTtraceable calibrations of all or portions of particular sensors, DAUs, or DASs to monitor the performance of vendors and of ANSS networks. Such tests will be generally similar to all or portions of performance-verification tests.

The ANSS may maintain a testing laboratory at the USGS Albuquerque Seismological Laboratory. It may cooperate with Sandia National Laboratory and other ANSS and IRIS institutions in the use of their testing facilities. Or, it may contract some tests to NIST-traceable testing facilities for acceptance tests, portions of routine tests, NIST-traceable calibrations, and 
authenticating portions of vendors' performance-verification testing, as deemed advisable prior to final award of contracts (using either vendor-donated or first-article examples of the instruments). 


\section{References Cited}

Boore, D.M., Gibbs, J.F., Joyner, W.B., and Tinsley, J.C., 2003, Estimated ground motion from the 1994 Northridge, California, earthquake at the site of the Interstate 10 and La Cienega Boulevard bridge collapse, West Los Angeles, California: Seismological Society of America Bulletin, v. 93, no. 6, p. 2737-2751.

Evans, J.R., Hamstra, Jr., R.H., Kündig, C., Camina, P., and Rogers, J.A., 2005, TREMOR-A wireless MEMS accelerograph for dense arrays: Earthquake Spectra, v. 21, no. 1, p. 91-124.

International Association of Seismology and Physics of the Earth's Interior (IASPEI), 2002, New manual on seismic observatory practice: http://www.iaspei.org. Accessed 15 July 2008.

MatLab ${ }^{\mathrm{TM}}$, "GST_NoiseAndRangeStandard.m," “GST_NormalizedWelch.m” scripts and related functions: http://earthquake.usgs.gov/research/monitoring/anss/documents.php. Accessed 15 July 2008.

U.S. Geological Survey, 1999, An assessment of seismic monitoring in the United StatesRequirements for an advanced national seismic system: U.S. Geological Survey Circular $1188,55 \mathrm{p}$.

U.S. Geological Survey, ANSS Structural Response Monitoring Committee, 2005, Guideline for ANSS seismic monitoring of engineered civil systems-Version 1.0: U.S. Geological Survey Open-File Report 05-1039, 49 p., http://pubs.usgs.gov/of/2005/1039/of2005-1039.pdf. Accessed 15 July 2008.

U.S. Geological Survey, ANSS Technical Integration Committee, 2002, Technical guidelines for the implementation of the Advanced National Seismic System-Version 1.0: U.S. Geological Survey Open-File Report 02-0092, 92 p., http://pubs.usgs.gov/of/2002/ofr-02-0092/ofr-020092.pdf. Accessed 15 July 2008. 
Wald, D. J., Quitoriano, V., Heaton, T.H., Kanamori, H., Scrivner, C.W., and Worden, C.B., 1999, TriNet "ShakeMaps"-_Rapid generation of instrumental ground motion and intensity maps for earthquakes in southern California: Earthquake Spectra, v. 15, no. 3, p. 537-555. 


\title{
10 Appendix: The Working Group on Instrumentation, Siting, \\ Installation, and Site Metadata
}

\author{
Steve Estes \\ Alaska Earthquake Information Center \\ Geophysical Institute \\ University of Alaska \\ 903 Koyukuk Drive \\ P.O. Box 757320 \\ Fairbanks, AK 99775-7320 \\ 907-474-7425 \\ estes@gi.alaska.edu \\ John R. Evans \\ U.S. Geological Survey \\ 345 Middlefield Rd, M.S. 977 \\ Menlo Park, CA 94025-3591 \\ 650-329-4753 \\ jrevans@usgs.gov \\ Susan E. Hough \\ U.S. Geological Survey \\ 525 S. Wilson Avenue \\ Pasadena, CA 91106-3212 \\ 626-583-7224 \\ hough@usgs.gov \\ Charles R. Hutt (chair) \\ Albuquerque Seismological Laboratory \\ U.S. Geological Survey \\ P.O. Box 82010 \\ Albuquerque, NM 87198-2010 \\ 505-846-5649 \\ bhutt@usgs.gov
}

\author{
Richard P. "Dick” Kromer \\ rpkromer Consulting \\ 5309 Dee Drive NE \\ Albuquerque, NM 87111 \\ 505-298-3073 \\ rpkromer@,comcast.net \\ Robert L. Nigbor \\ University of California at Los Angeles \\ Department of Civil Engineering \\ Boelter Hall 5731 \\ Los Angeles, CA 90095-1593 \\ 310-825-3492 \\ nigbor@ucla.edu \\ William U. Savage \\ U.S. Geological Survey \\ 345 Middlefield Road, M.S. 977 \\ Menlo Park, CA 94025-3591 \\ 650-329-4852 \\ wusavage@usgs.gov \\ Jamison Steidl \\ University of California at Santa Barbara \\ Institute for Crustal Studies \\ Santa Barbara, CA 93106 \\ 805-893-4905 \\ steidl@crustal.ucsb.edu \\ Robert Uhrhammer \\ University of California \\ Berkeley Seismological Lab \\ 475 McCone Hall \\ Berkeley, CA 94720-4760 \\ 510-642-8504 \\ bob@seismo.berkeley.edu
}


